
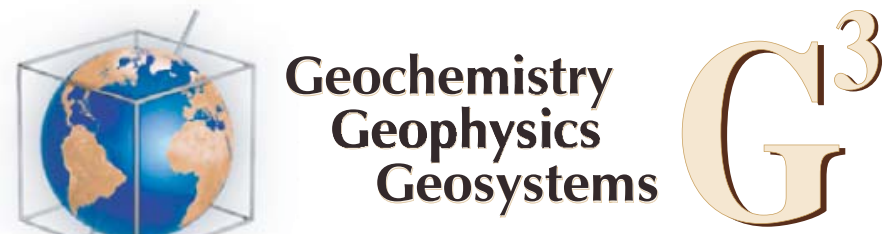

\title{
X-ray magnetic circular dichroïsm provides strong evidence for tetrahedral iron in ferrihydrite
}

\author{
Yohan Guyodo, Philippe Sainctavit, Marie-Anne Arrio, and Claire Carvallo \\ Institut de Minéralogie et de Physique des Milieux Condensés (UMR7590: CNRS-UPMC-IPGP- \\ IRD), FR-75252 Paris CEDEX 05, France (yohan.guyodo@impmc.upmc.fr)
}

\author{
R. Lee Penn, Jasmine J. Erbs, and Brady S. Forsberg \\ Department of Chemistry, University of Minnesota, Twin Cities, Minneapolis, Minnesota 55455, USA
}

\section{Guillaume Morin and Fabien Maillot}

Institut de Minéralogie et de Physique des Milieux Condensés (UMR7590: CNRS-UPMC-IPGPIRD), FR-75252 Paris CEDEX 05, France

\section{France Lagroix}

Institut de Physique du Globe de Paris, FR-75238 Paris CEDEX 05, France

\section{Pierre Bonville}

Service de Physique de l'Etat Condensé (CEA/IRAMIS/SPEC), FR-91191 Gif-sur-Yvette, France

\author{
Fabrice Wilhelm and Andrei Rogalev \\ European Synchrotron Radiation Facility, FR-38000 Grenoble, France
}

[1] Ferrihydrite is an important iron oxyhydroxide for earth and environmental sciences, biology, and technology. Nevertheless, its mineral structure remains a matter of debate. The stumbling block is whether a significant amount of tetrahedrally coordinated iron is present. Here we present the first X-ray magnetic circular dichroïsm (XMCD) measurements performed on a well characterized synthetic sample of 6-line ferrihydrite, at both $\mathrm{K}$ and $\mathrm{L}_{2,3}$ energy edges of iron. XMCD results demonstrate unambiguously the presence of tetrahedrally coordinated Fe(III) in the mineral structure, in quantities compatible with the latest extended X-ray absorption fine structure (EXAFS) analyses suggesting a concentration of 20-30\%. Moreover, we find an antiferromagnetic coupling between tetrahedral and octahedral sublattices, with the octahedral sublattice parallel to the external magnetic field.

Components: 5100 words, 3 figures.

Keywords: XMCD; ferrihydrite; magnetic properties.

Index Terms: 1512 Geomagnetism and Paleomagnetism: Environmental magnetism; 1519 Geomagnetism and Paleomagnetism: Magnetic mineralogy and petrology; 1540 Geomagnetism and Paleomagnetism: Rock and mineral magnetism.

Received 6 April 2012; Revised 8 May 2012; Accepted 8 May 2012; Published 7 June 2012. 
Guyodo, Y., et al. (2012), X-ray magnetic circular dichroïsm provides strong evidence for tetrahedral iron in ferrihydrite, Geochem. Geophys. Geosyst., 13, Q06Z44, doi:10.1029/2012GC004182.

Theme: Magnetism From Atomic to Planetary Scales: Physical Principles and Interdisciplinary Applications in Geosciences and Planetary Sciences

\section{Introduction}

[2] Ferrihydrite is a widespread iron oxyhydroxide, which is present in diverse environments including soils, sediments, groundwaters and streams, and constitutes the mineral core of ferritin, a vital iron storage protein [Cornell and Schwertmann, 2003; Gossuin et al., 2009; Jambor and Dutrizac, 1998; Lewin et al., 2005; Muller et al., 2005; Rancourt et al., 2001; Schwertmann et al., 1987]. It is one of the first solids to precipitate after mineral weathering and exists only as nanoparticles. Ferrihydrite is considered to be a precursor for more crystalline, larger minerals such as goethite, maghemite, or hematite, and therefore plays a key role in understanding mineralization pathways and more generally the biochemical cycling of iron in the environment [e.g., Barrón et al., 2003; Burleson and Penn, 2006; Coker et al., 2006; Cornell and Schwertmann, 2003; Guyodo et al., 2003; Hochella et al., 2008; Penn et al., 2007]. For example, ferrihydrite is present in acid mine drainages, where it favors the sequestration of contaminants such as arsenic because of its high surface reactivity [e.g., Cornell and Schwertmann, 2003]. The most common reported forms of ferrihydrite are two-line and sixline ferrihydrite, which are characterized by two and six poorly resolved x-ray diffraction (XRD) peaks, respectively [Cornell and Schwertmann, 2003; Jambor and Dutrizac, 1998]. In terms of its magnetic properties, ferrihydrite is considered as an antiferromagnetic mineral with an associated ferromagneticlike magnetic structure due to uncompensated moments [Berquó et al., 2007; Gilles et al., 2002; Guyodo et al., 2006; Murad, 1988]. Nanoparticles of ferrihydrite have low temperature magnetic properties that are characteristic of superparamagnetic systems. This magnetic behavior is also observed in Mössbauer spectra, which have developed sextets only below size-dependent blocking temperatures [Berquó et al., 2007; Guyodo et al., 2006]. These spectra are characterized by relatively large hyperfine field distributions inherent to poorly crystalline nanoparticle assemblages, which makes them unsuitable for detailed mineral structure studies.
[3] To date, the mineral structure of ferrihydrite remains fairly elusive, despite considerable research efforts [Carta et al., 2009; Drits et al., 1993; Eggleton and Fitzpatrick, 1988; Harrington et al., 2011; Janney et al., 2000, 2001; Jansen et al., 2002; Maillot et al., 2011; Manceau, 2009; Manceau and Drits, 1993; Michel et al., 2007; Rancourt and Meunier, 2008; Zhao et al., 1994]. A key aspect of the problem resides in quantifying the presence - or absence - of a substantial amount of tetrahedrally coordinated $\mathrm{Fe}(\mathrm{III})$ in the mineral structure. A recent study proposed a single structure by analyzing the pair distribution function (PDF) derived from direct Fourier transformation of total x-ray scattering [Michel et al., 2007]. This model structure incorporates $20 \%$ of tetrahedrally coordinated Fe(III) [Harrington et al., 2011; Michel et al., 2007]. These studies contradict previous results based on extended x-ray absorption fine structure (EXAFS), which proposed a structure based on mixed phases without tetrahedral Fe(III) [Drits et al., 1993; Manceau and Drits, 1993]. However, according to others, the PDF analysis-based model appears to fail at reproducing the data in reciprocal space [Carta et al., 2009; Manceau, 2009; Rancourt and Meunier, 2008]. Nonetheless, a recent x-ray absorption near-edge structure (XANES) study suggested either the presence of a certain amount of tetrahedral iron or the presence of an asymmetric octahedral coordination [Carta et al., 2009]. More recently, a detailed EXAFS study of well characterized ferrihydrite samples pointed to the presence of a significant amount of tetrahedrally coordinated $\mathrm{Fe}(\mathrm{III})$ in the mineral structure, ranging between 20 and 30\% [Maillot et al., 2011].

[4] We present results from X-ray magnetic circular dichroïsm (XMCD) measurements performed on a synthetic sample of 6-line ferrihydrite. XMCD is a synchrotron radiation based technique sensitive to the magnetic properties of materials [Sainctavit et al., 2003]. It is element specific and does not depend on the existence of a long-range periodic structure, being thus adapted to low-crystallinity mineral phases and small particle sizes. Because of its high sensitivity to site occupancy, XMCD can be used to prove 
unambiguously the presence of tetrahedrally coordinated ions in iron oxides or oxyhydroxides [BriceProfeta et al., 2005; Carvallo et al., 2008, 2010; Coker et al., 2007; Pearce et al., 2006; Sikora et al., 2010]. At $\mathrm{L}_{2,3}$ edges, for instance, XMCD can be interpreted in terms of the Ligand Field Multiplet method in the electric dipole approximation. The essential ingredients of this method are the atomic spherical contributions of the Hamiltonian (i.e., kinetic energy, electron-nucleus Coulomb attraction, electron-electron Coulomb repulsion and spin-orbit coupling) and a non-spherical contribution. In this framework, the spherical terms are nearly identical for all $\mathrm{Fe}$ (III) ions, while the non-spherical terms are sensitive to the coordination shell (i.e., number and nature of the neighboring ions, spin and orbit magnetic moments). These terms are, however, practically not sensitive to the environment beyond the coordination shell (i.e., the crystallographic structure). From what precedes, the XMCD signal can thus basically distinguish contributions from $\mathrm{Fe}(\mathrm{III})$ versus $\mathrm{Fe}(\mathrm{II})$ ions, $\mathrm{Fe}(\mathrm{III})$ ions on octahedral sites versus $\mathrm{Fe}(\mathrm{III})$ on tetrahedral sites, and $\mathrm{Fe}$ spin and orbit magnetic moments parallel versus antiparallel to the external magnetic field.

[5] The XMCD data obtained on our 6-line ferrihydrite sample are compared to the same data acquired on well characterized maghemite samples. XMCD experiments were carried out both at the $\mathrm{L}_{2,3}$ and $\mathrm{K}$ edges of iron. XMCD recorded at the $\mathrm{L}_{2,3}$-edge were acquired on the SIM beam line of the Swiss Light Source (SLS) using the Total Electron Yield (TEY) detection mode, while XMCD recorded at the K-edge were acquired on the ID12 beamline of the European Synchrotron Radiation Facility (ESRF) using the Fluorescence Yield (FY) detection mode. Due to sample availability constraints at the time of measurement, two distinct maghemite reference samples were used at ESRF and SLS with identical crystallinity but slightly different average particle sizes.

\section{Sample Preparation and Characterization}

[6] A well characterized sample of 6-line ferrihydrite (Fh) and two reference maghemite samples (Mh1, Mh2) were synthesized for this XMCD study. All samples were prepared by reproducing thoroughly tested synthesis methods [Cornell and Schwertmann, 2003; David and Welch, 1956; Erbs et al., 2008; Maillot et al., 2011; Vayssières et al., 1998; Wang et al., 2008]. Following standard practice, all samples were dried as soon as synthesized to prevent any mineral change and stored in sealed containers.

[7] The 6-line ferrihydrite sample (Fh) was prepared by following the method of Erbs et al. [2008]. In this procedure, a ferrihydrite suspension was prepared by the controlled addition of a $0.48 \mathrm{M}$ $\mathrm{NaHCO}_{3}$ (Mallinckrodt) solution to an equal volume of $0.40 \mathrm{M} \mathrm{Fe}\left(\mathrm{NO}_{3}\right)_{3} \cdot 9 \mathrm{H}_{2} \mathrm{O}$ (Fisher) with vigorous stirring. In this method, the ferric nitrate solution is equilibrated to a specific temperature using a heated water bath [Erbs et al., 2008]. The water bath temperature was maintained at $52^{\circ} \mathrm{C}$.

[8] The maghemite reference sample used at SLS (Mh1) was synthesized using well established methods [Cornell and Schwertmann, 2003; David and Welch, 1956] by first preparing $280 \mathrm{~mL}$ of a solution of $0.3 \mathrm{M} \mathrm{Fe}(\mathrm{II})$ sulphate (Fisher) with deionized Milli-Q water (18.2 $\mathrm{M} \Omega$ ) which was degassed with $\mathrm{N}_{2}$, and heated to $90^{\circ} \mathrm{C}$. To this solution, $120 \mathrm{~mL}$ of degassed $0.27 \mathrm{M} \mathrm{KNO}_{3}$ (Fisher) in $3.33 \mathrm{M} \mathrm{KOH}$ (Mallinckrot) was added dropwise over the course of a few minutes. The reaction solution was maintained at $90^{\circ} \mathrm{C}$ for an additional $60 \mathrm{~min}$ with magnetic stirring. The precipitated magnetite was magnetically decanted from the mother liquor, and was allowed to cool and dry in a number of weigh boats. The entire preparation was carried out inside a Coy Laboratory Products anaerobic chamber $\left(\mathrm{N}_{2}\right.$ with $\left.4-5 \% \mathrm{H}_{2}\right)$ [David and Welch, 1956]. The magnetite particles were then placed within a constant temperature furnace at $250^{\circ} \mathrm{C}$ for $5 \mathrm{~h}$ under atmospheric conditions, resulting in complete oxidation of magnetite to maghemite [Cornell and Schwertmann, 2003].

[9] The synthesis procedure and full characterization of the maghemite reference sample used at ESRF (Mh2) is described by Maillot et al. [2011]. It was prepared at room temperature through complete oxidation by hydrogen peroxide of a synthetic magnetite obtained from aqueous coprecipitation of $\mathrm{Fe}(\mathrm{II})$ and $\mathrm{Fe}(\mathrm{III})$ at $\mathrm{pH}=7$ in a Jacomex ${ }^{\circledR}$ glove box under $\mathrm{N}_{2}$ atmosphere $\left(<50 \mathrm{ppm}_{2}\right)$ [David and Welch, 1956], following the procedure of Vayssières et al. [1998].

[10] XRD patterns for our three samples are displayed in Figure 1a, while additional characterizations have been described in previous publications [Cornell and Schwertmann, 2003; David and Welch, 1956; Erbs et al., 2008; Maillot et al., 2011; Vayssières et al., 1998; Wang et al., 2008]. As anticipated, the XRD patterns for our samples have peak positions and intensities expected for ferrihydrite and maghemite. 

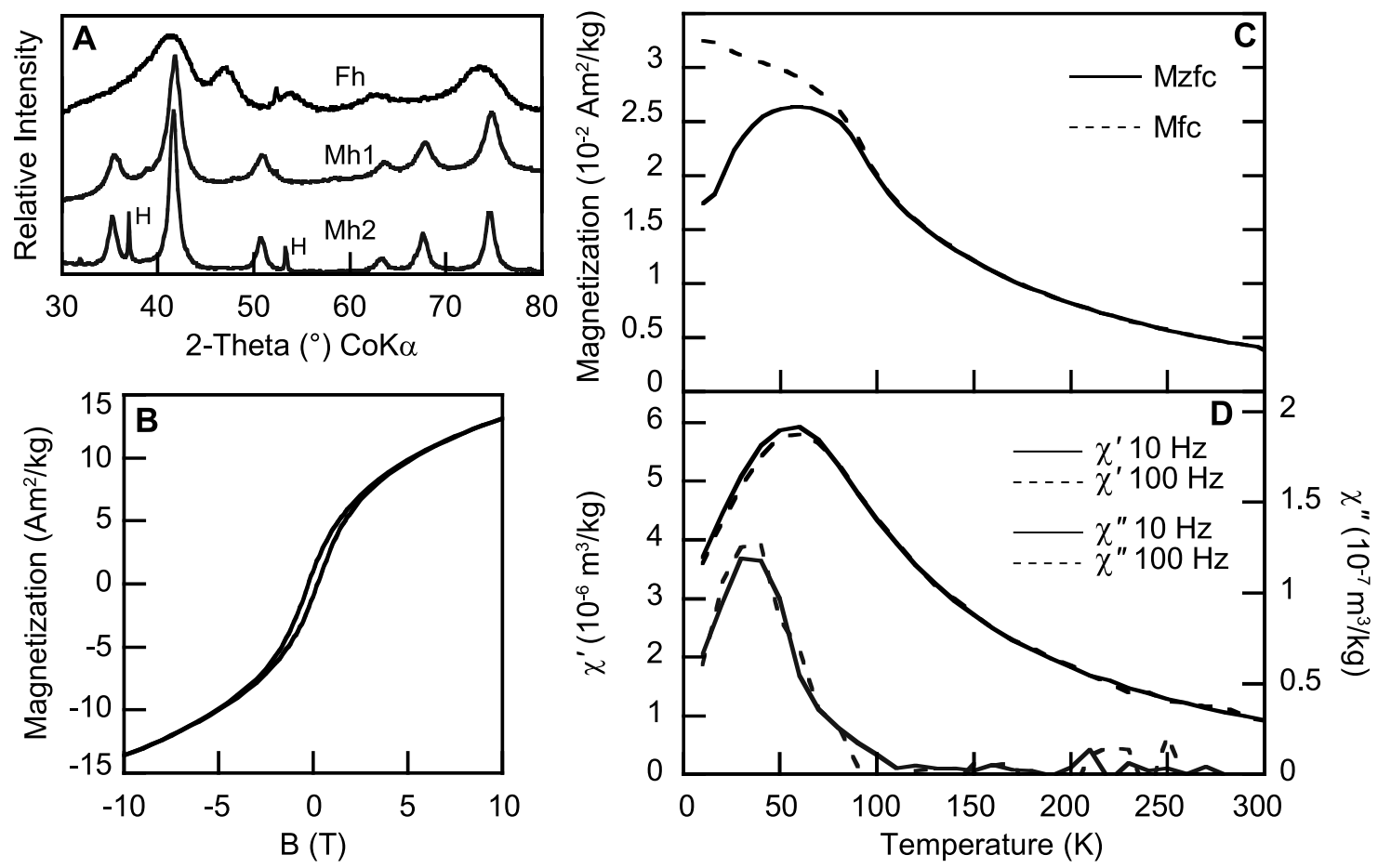

Figure 1. (a) X-ray diffraction spectra of the three samples: ferrihydrite (Fh), maghemite (Mh1 and Mh2). Peaks labeled $\mathrm{H}$ correspond to halite $(\mathrm{NaCl})$. (b) Magnetic hysteresis loop of sample $\mathrm{Fh}$ between -10 and $+10 \mathrm{~T}$, at $5 \mathrm{~K}$. (c) Field cooled (Mfc) and zero field cooled (Mzfc) induced magnetizations obtained with a 5 mT field. (d) Lowtemperature in-phase $\left(\chi^{\prime}\right)$ and quadrature $\left(\chi^{\prime \prime}\right)$ alternating field magnetic susceptibility with driving field frequencies of 10 and $100 \mathrm{~Hz}$.

[11] Further characterization of the 6-line ferrihydrite sample was achieved by measuring its lowtemperature magnetic properties, which have been shown to be dependent on particle size and crystallinity [Berquó et al., 2007; Guyodo et al., 2006]. Measurements were performed on dry powders using a high-field vibrating sample magnetometer (VSM) and a magnetic properties measurement system (MPMS). Representative results are shown in Figure 1. As expected from previous studies of 6-line ferrihydrite, our sample has magnetic hysteresis (i.e., an open loop) at $5 \mathrm{~K}$ (Figure 1b), with a coercivity (Bc) value of about $255 \mathrm{mT}$, which is comparable to other published data [Guyodo et al., 2006]. In addition, the magnetization does not saturate (i.e., it is not independent of the magnetic field), even in a magnetic field as large as $10 \mathrm{~T}$, as can be expected from an antiferromagnetic mineral. Low-temperature field-cooled (Mfc) and zero-field cooled (Mzfc) induced magnetizations were measured with a DC field of $5 \mathrm{mT}$ (Figure 1c). In the Mzfc experiment, the samples were cooled in zero field prior to measurement. In the Mfc experiment, the samples were cooled in a $5 \mathrm{mT}$ magnetic field, and the induced magnetization was subsequently measured in the same applied field, during warming to room temperature. The Mzfc curve has a peak at $60 \mathrm{~K}$, which marks the mean of the thermal unblocking temperature distribution of superparamagnetic particles (Tb). The temperature at which Mfc and Mzfc curves merge, called the irreversible temperature (Tirr), corresponds to the temperature above which all particles are in a superparamagnetic state. The difference in magnetization between Mfc and Mzfc curves, below Tirr can thus be explained by the acquisition of a remanent magnetization by the particles while blocking in an external field [Dormann et al., 1997]. In addition, low-temperature alternating field magnetic susceptibility values were measured from 10 to $300 \mathrm{~K}$. The in-phase $\left(\chi^{\prime}\right)$ and quadrature $\left(\chi^{\prime \prime}\right)$ components of the magnetic susceptibility were acquired in a $10^{-4} \mathrm{~T}$ driving field oscillating at frequencies of 10 and $100 \mathrm{~Hz}$ (Figure 1d). The temperature evolution of $\chi^{\prime}$ is characterized by a peak at about $60 \mathrm{~K}$, with a slight frequency dependency, highlighted by the presence of a peak in $\chi^{\prime \prime}$ [Néel, 1949]. This observation is consistent with the thermal unblocking of superparamagnetic particles, and has been observed in previous studies of well characterized synthetic 6line ferrihydrite samples [Berquó et al., 2007; Guyodo et al., 2006]. Considering the transmission 

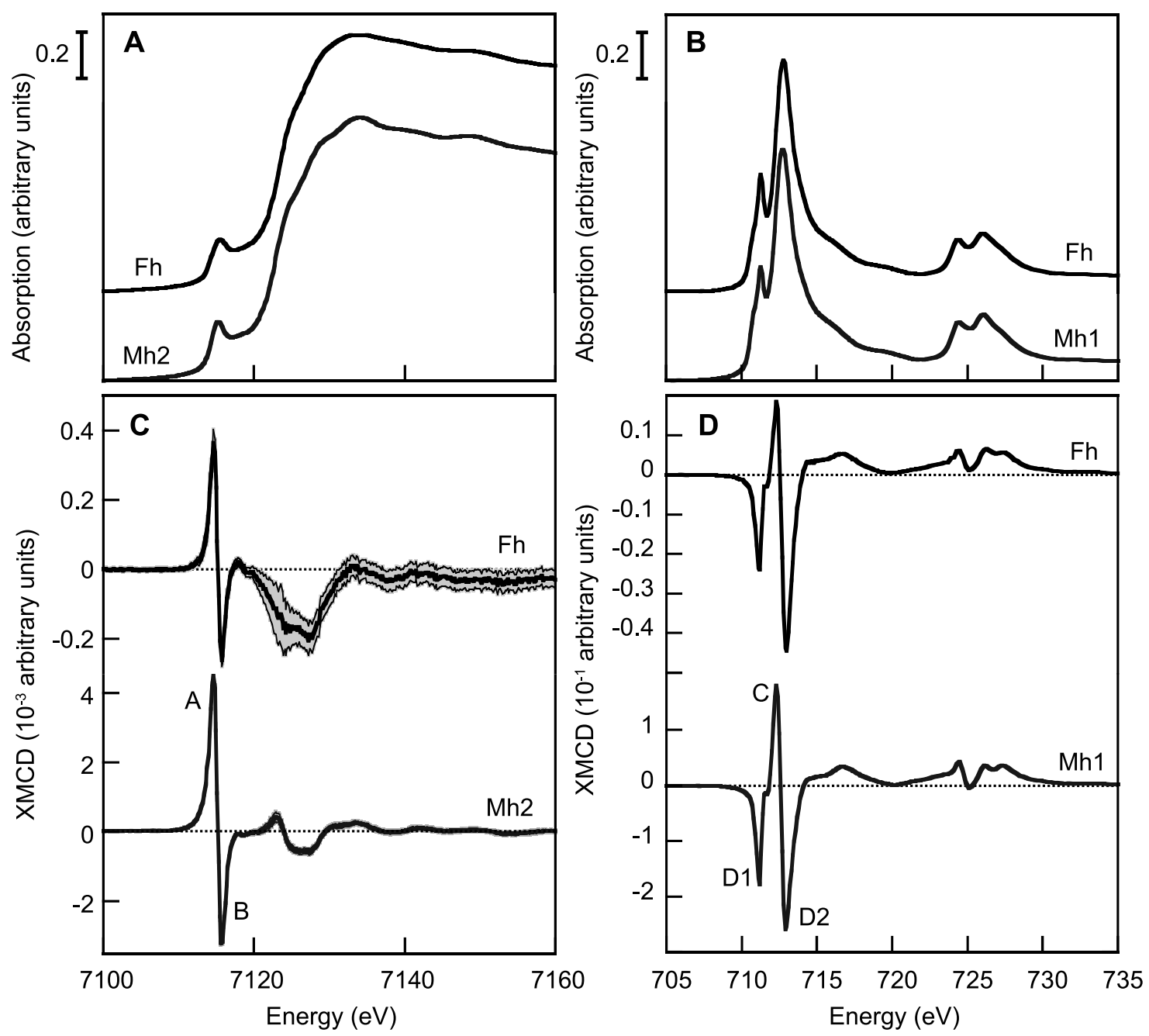

Figure 2. ( $\mathrm{a}$ and b) XAS normalized spectra of ferrihydrite and maghemite at the iron $\mathrm{K}$ and $\mathrm{L}_{2,3}$ edges, respectively. ( $\mathrm{c}$ and d) Corresponding XMCD spectra of ferrihydrite and maghemite. Two-sigma standard errors are represented as gray shading in Figure 2c and are smaller than the line thickness in Figure 2d.

electron microscopy based particle sizes reported at different temperatures for our synthesis procedure [Erbs et al., 2008] and a sample synthesis temperature of $52^{\circ} \mathrm{C}$, the average particle size of our $\mathrm{Fh}$ sample is estimated to be around $4.4 \mathrm{~nm}$. In view of the blocking temperatures reported by Guyodo et al. [2006] and associated average particle sizes, Tb determined from data in Figures 1c and 1d of our synthetic Fh sample is compatible with a particle size of $4.4 \mathrm{~nm}$. Overall, the low temperature magnetic data acquired on our Fh sample are characteristic of genuine, standard 6-line ferrihydrite nanoparticles.

\section{XMCD Measurements}

[12] Iron $\mathrm{L}_{2,3}$ and $\mathrm{K}$ edge $\mathrm{XMCD}$ measurements were performed following well established experimental procedures for the SIM beamline at SLS [Carvallo et al., 2008] and for the ID12 beamline at ESRF [Carvallo et al., 2010; Rogalev et al., 2001]. XMCD spectra were obtained by taking the direct difference between two $\mathrm{x}$-ray absorption spectra (XAS) successively collected with left- then right-circularly polarized $\mathrm{x}$-rays in the presence of a magnetic field. In this study, all XMCD spectra were measured after cooling the samples to below $15 \mathrm{~K}$, well below $\mathrm{Tb}$ of our Fh sample, in order to perform measurements on particles in a stable magnetic state. Furthermore, an external magnetic field of $\pm 6 \mathrm{~T}$ was applied to maximize the magnetic signal carried by ferrihydrite. At ESRF, measurements were acquired on $10 \mathrm{~mm}$ diameter pellets made from the initially powdered samples, while at SLS, samples were obtained by drop-casting on copper plates. The signal-to-noise ratio was improved by calculating average XMCD based on multiple individual 

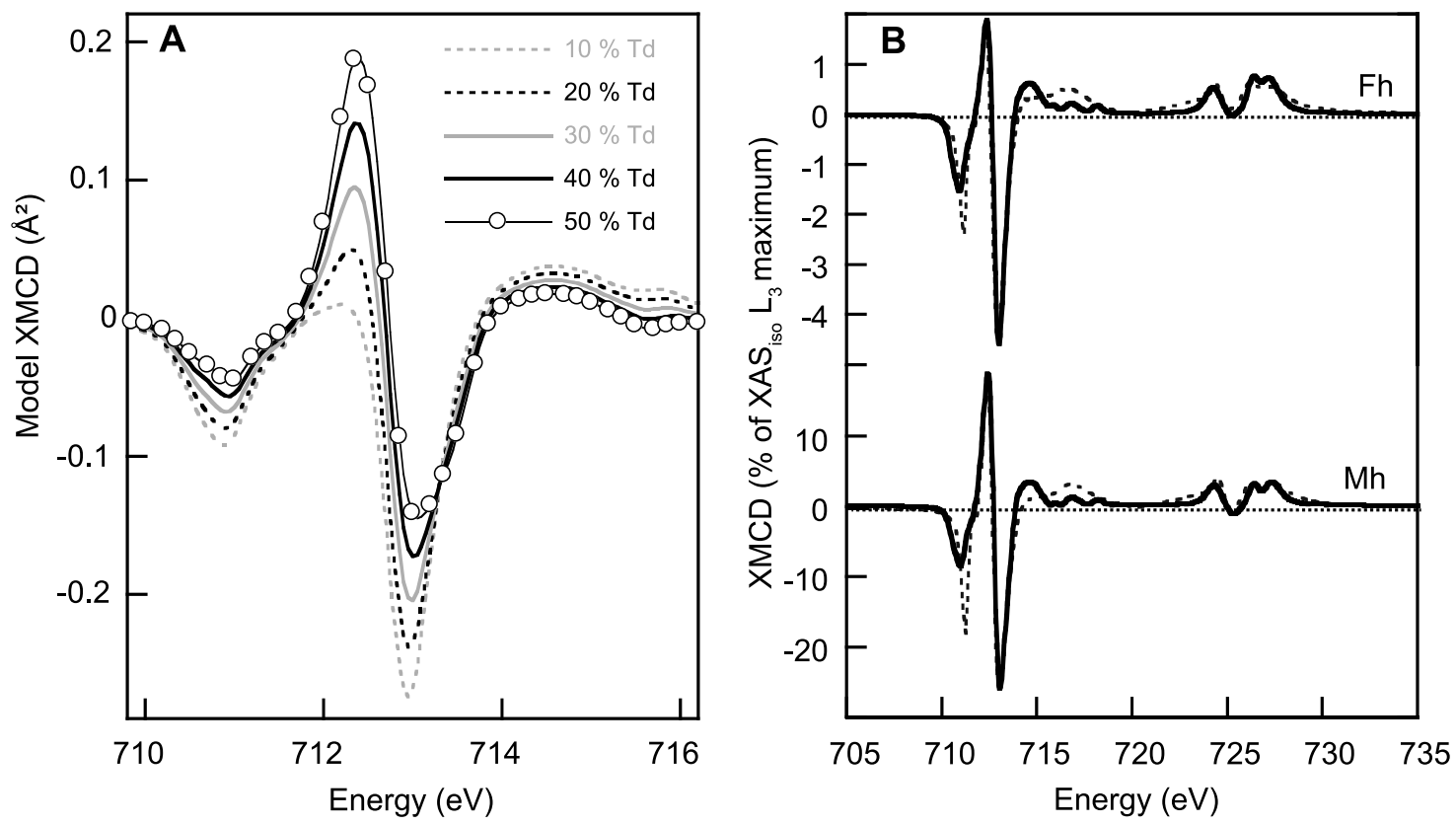

Figure 3. (a) Illustration of the effect of varying the amount of tetrahedral $\mathrm{Fe}(\mathrm{III})$ on the shape of calculated XMCD spectra: theoretical cross-sections are expressed in $\AA^{2}$. (b) Calculated XMCD spectra with $28 \%$ and $37.5 \%$ of tetrahedral Fe(III) (black solid line), to be compared to the experimental XMCD data (gray dotted line) for ferrihydrite and maghemite, respectively: experimental cross-sections are expressed as a percentage of the $\mathrm{L}_{3}$ maximum for the isotropic XAS, i.e., $\left(\mathrm{s}_{\text {Left }}+\mathrm{s}_{\text {Right }}\right) / 2$.

measurements. In order to make sure that the measured XMCD spectra are free of artifacts, we verified that spectra obtained in $-6 \mathrm{~T}$ were opposite to those obtained in $+6 \mathrm{~T}$.

[13] XMCD results are shown in Figure 2, where black lines represent ferrihydrite and gray lines represent maghemite. Figures $2 \mathrm{a}$ and $2 \mathrm{~b}$ represent average isotropic XAS acquired at the iron $\mathrm{K}$ and $\mathrm{L}_{2,3}$ edges, respectively. Isotropic XAS were normalized to 1 well above the edge for K-edge measurements, and normalized to 1 at the peak of the $\mathrm{L}_{3}$ edge for $\mathrm{L}_{2,3}$ edge measurements. The resulting isotropic XAS are similar to previously published data [Brice-Profeta et al., 2005; Carvallo et al., 2008, 2010; Guyodo et al., 2006; Maillot et al., 2011; Zhao et al., 1994]. In Figures 2c and 2d, the overall intensity of the ferrihydrite XMCD features is about an order of magnitude smaller than that of maghemite. This result is consistent with the difference in spontaneous magnetization between the two minerals (maghemite saturation magnetization is about $80 \mathrm{Am}^{2} / \mathrm{kg}$ [Hunt et al., 1995], while the magnetization at $6 \mathrm{~T}$ of our ferrihydrite sample is about $10 \mathrm{Am}^{2} / \mathrm{kg}$, Figure 1). This again attests that the measured XMCD spectra reflect efficiently the bulk magnetic properties of our sample. At K-edge, previous studies have shown that maghemite pre-edge XMCD features (labeled $\mathrm{A}$ and $\mathrm{B}$ on Figure 2c) are due to Fe(III) located at tetrahedral sites, because octahedral sites provide only small effects [Carvallo et al., 2010; Sikora et al., 2010]. In Figure 2c, the shape and energy positions of these features are similar to previously published data [Carvallo et al., 2010]. Theoretical calculations [Sikora et al., 2010] have shown that the A and B features could be fully interpreted as originating from $\mathrm{Fe}(\mathrm{III})$ on tetrahedral sites. Strikingly, these features are also clearly present in the XMCD data of our Fh sample. This observation provides unambiguous support in favor of the most recent EXAFS analysis of 6-line ferrihydrite [Maillot et al., 2011], which suggests the presence of a significant amount of tetrahedral iron in Fh. At the $\mathrm{L}_{2,3}$ edge, maghemite XMCD features are also similar to previously published data [Brice-Profeta et al., 2005; Carvallo et al., 2008]. At the $\mathrm{L}_{3}-$ edge, according to previous multiplet theory calculations [Brice-Profeta et al., 2005], the positive peak labeled as $\mathrm{C}$ on Figure $2 \mathrm{~d}$ is due to tetrahedral iron, while the two negative peaks labeled as D1 and D2 in Figure 2d are due to octahedral iron. At the $\mathrm{L}_{2}$-edge, the peaks remain essentially positive, 
with slight variations due to the competing influence of the tetrahedral and octahedral sites. Again, as observed at K-edge, the shape of the Fh XMCD spectrum is similar to that of Mh1. Provided the presence of a well-developed positive peak at the $\mathrm{L}_{3}$-edge in $\mathrm{Fh}$, and provided that the peaks observed at the $\mathrm{L}_{3}$ and $\mathrm{L}_{2}$ edges of $\mathrm{Fh}$ are located at the same energies as in Mh1, our data confirm the presence of a significant amount of tetrahedral $\mathrm{Fe}$ (III) in Fh. The ratio of the C to D2 peaks in Fh is, however, lower than in maghemite, which suggests a lower amount of tetrahedral iron. We used the Ligand Field Multiplet model [de Groot and Kotani, 2008; Thole et al., 1985] to calculate the $\left[\mathrm{Fe}_{\mathrm{Td}}\right] /\left(\left[\mathrm{Fe}_{\mathrm{Td}}\right]+\left[\mathrm{Fe}_{\mathrm{Oh}}\right]\right)$ tetrahedral vs octahedral contributions to the XMCD for Mh1 and Fh, using our well established previous calculation for maghemite nanoparticles and the same ligand field parameters [Brice-Profeta et al., 2005]. An illustration of these calculations is shown in Figure 3a, where several model XMCD spectra were calculated for various tetrahedral contributions. It is clear from Figure 3a that the C and D2 peaks have the greatest sensitivity to the tetrahedral versus octahedral contributions. Using these calculations, we confirm that Mh contains $37.5 \pm 3 \%$ of tetrahedral iron as expected for stoichiometric maghemite (Figure $3 \mathrm{~b}$ ). Based on these parameters, calculation of the Fh XMCD spectrum indicates that 6-line Fh contains $28 \pm 3 \%$ of tetrahedral iron (Figure $3 \mathrm{~b}$ ). One should keep in mind, however, that maghemite and Fh do not share exactly the same magnetic characteristics. Maghemite is ferrimagnetic with a magnetic moment that is well saturated below the applied field of $6 \mathrm{~T}$, while $\mathrm{Fh}$ is not saturated in $6 \mathrm{~T}$ and is currently thought of as an imperfect antiferromagnetic mineral with non-compensated moments. The magnetization carried by the uncompensated moments has been shown to be size dependent [Guyodo et al., 2006]. As a consequence, to some extent, the XMCD signal may also be size dependent. It is also possible that the value of $28 \%$ for tetrahedral iron found here depends on whether the distribution of the non-compensated moments is homogenous between octahedral and tetrahedral sites. Distinguishing between core and surface contributions may be difficult. At $\mathrm{L}_{2,3}$ edge, the TEY detection mode is sensitive to the top $10 \mathrm{~nm}$ of the sample. Since Fh nanoparticles are less than $5 \mathrm{~nm}$, the whole volume of the nanocrystallites is probed, and surface and core both contribute to the XMCD signal. At K-edge, the penetration depth of the FY detection mode is larger than $1000 \mathrm{~nm}$, probing large clusters of nanoparticles. The fact that $\mathrm{XMCD}$ in the pre-edge region from $\mathrm{Fh}$ and $\mathrm{Mh}$ have similar shape is a confirmation that the similarities observed at $\mathrm{Fe}_{2,3}$ edge are indeed observed with a larger penetration depth at Fe K-edge.

\section{Conclusions}

[14] Results from the first XMCD investigation of a synthetic sample of 6-line ferrihydrite at both $\mathrm{K}$ and $\mathrm{L}_{2,3}$ edges of iron provide strong evidence for the presence of a significant amount of tetrahedrally coordinated $\mathrm{Fe}(\mathrm{III})$ in the mineral structure. With respect to the ongoing debate about the mineral structure of ferrihydrite, our results support recent studies that advocate the presence of 20 to $30 \%$ of tetrahedral iron. Although a detailed structural model remains to be established, our findings represent the first direct experimental evidence for the presence of tetrahedral Fe(III) in ferrihydrite. This direct evidence is confirmed by Ligand Field Multiplet calculations. Moreover, we find an antiferromagnetic coupling between the sublattices of $\mathrm{Fe}_{\mathrm{Td}}$ sites and $\mathrm{Fe}_{\mathrm{Oh}}$ sites, with the $\mathrm{Fe}_{\mathrm{Oh}}$ sublattice parallel to the external magnetic field. Since XMCD at K and $\mathrm{L}_{2,3}$ edges is almost insensitive to the iron environment beyond the coordination shell, we cannot propose a definite crystallographic structure from our measurements. Nonetheless, our present results place a strong constraint on future structural models based on crystallographic experiments. In addition, further XMCD measurements should be performed on other samples to test the possible influence of crystallinity (e.g., 2-line versus 6-line) on the magnetic structure of ferrihydrite.

\section{Acknowledgments}

[15] This work was supported by the French Agence Nationale de la Recherche (ANR-2010-BLAN-604-01, ANR-06-JCJC0144), the National Science Foundation (EAR-0311869, Career Grant 0346385, IGERT Program Award DGE-0114372), the University of Minnesota, SLS (beamtime allocation 20090237), and ESRF (beamtime allocation HE-3140). We acknowledge the staff at SLS and ESRF for their help during XMCD measurements, particularly Frithjof Nolting and Loïc LeGuyader from SIM beamline. This manuscript benefited from comments provided by the Associate Editor (A. P. Roberts) and three anonymous reviewers. IPGP contribution 3290.

\section{References}

Barrón, V., J. Torrent, and E. de Grave (2003), Hydromaghemite, an intermediate in the hydrothermal transformation of 2-line ferrihydrite into hematite, Am. Mineral., 88, 1679-1688.

Berquó, T. S., S. K. Banerjee, R. G. Ford, R. L. Penn, and T. Pichler (2007), High crystallinity Si-ferrihydrite: An 
insight into its Néel temperature and size dependence of magnetic properties, J. Geophys. Res., 112, B02102, doi:10.1029/ 2006JB004583.

Brice-Profeta, S., M.-A. Arrio, E. Tronc, N. Menguy, I. Letard, C. Cartier dit Moulin, M. Noguès, C. Chanéac, J. P. Jolivet, and P. Sainctavit (2005), Magnetic order in $\gamma-\mathrm{Fe}_{2} \mathrm{O}_{3}$ nanoparticles: A XMCD study, J. Magn. Magn. Mater., 288, 354-365, doi:10.1016/j.jmmm.2004.09.120.

Burleson, D. J., and R. L. Penn (2006), Two-step growth of goethite from ferrihydrite, Langmuir, 22, 402-409, doi:10.1021/ la051883g.

Carta, D., A. Casula, A. Corrias, A. Falqui, G. Navarra, and G. Pinna (2009), Structural and magnetic characterization of synthetic ferrihydrite nanoparticles, Mater. Chem. Phys., 113, 349-355, doi:10.1016/j.matchemphys.2008.07.122.

Carvallo, C., P. Sainctavit, M.-A. Arrio, N. Menguy, Y. Wang, G. OnaNguema, and S. Brice-Profeta (2008), Biogenic vs. abiogenic magnetite nanoparticles: A XMCD study, Am. Mineral., 93, 880-885, doi:10.2138/am.2008.2713.

Carvallo, C., P. Sainctavit, M.-A. Arrio, Y. Guyodo, R. L. Penn, B. Forsberg, A. Rogalev, F. Wilhelm, and A. Smekhova (2010), Self-reversal of magnetization in oceanic submarine basalts studied with XMCD, Geophys. Res. Lett., 37, L11306, doi:10.1029/2010GL043390.

Coker, V. S., A. G. Gault, C. I. Pearce, G. van der Laan, N. D. Telling, and J. M. Charnock (2006), XAS and XMCD evidence for species-dependent partitioning of arsenic during microbial reduction of ferrihydrite to magnetite, Environ. Sci. Technol., 40, 7745-7750, doi:10.1021/es060990+.

Coker, V. S., C. I. Pearce, C. Lang, G. van der Laan, R. A. D. Pattrick, N. D. Telling, D. Schuler, E. Arenholz, and J. R. Lloyd (2007), Cation site occupancy of biogenic magnetite compared to polygenic ferrite spinels determined by X-ray magnetic circular dichroism, Eur. J. Mineral., 19, 707-716, doi:10.1127/0935-1221/2007/0019-1758.

Cornell, R. M., and U. Schwertmann (2003), The Iron Oxides: Structure, Properties, Reactions, Occurrences and Uses, Wiley-VCH, Weinheim, Germany.

David, I., and A. J. E. Welch (1956), The oxidation of magnetite and related spinels. Constitution of gamma ferric oxide, Trans. Faraday Soc., 52, 1642-1650, doi:10.1039/tf9565201642.

de Groot, F. M. F., and A. Kotani (2008), Core Level Spectroscopy of Solids, Adv. Condens. Matter Sci., vol. 6, CRC Press, Boca Raton, Fla.

Dormann, J. L., D. Fiorani, and E. Tronc (1997), Magnetic relaxation in fine-particle systems, Adv. Chem. Phys., 98, 283-494, doi:10.1002/9780470141571.ch4.

Drits, V. A., B. A. Sakharov, A. L. Salyn, and A. Manceau (1993), Structural model for ferrihydrite, Clay Miner., 28, 185-207, doi:10.1180/claymin.1993.028.2.02.

Eggleton, R. A., and R. W. Fitzpatrick (1988), New data and a revised structural model for ferrihydrite, Clays Clay Miner., 36, 111-124, doi:10.1346/CCMN.1988.0360203.

Erbs, J. J., B. Gilbert, and R. L. Penn (2008), Influence of size on reductive dissolution of six-line ferrihydrite, J. Phys. Chem. C, 112, 12,127-12,133, doi:10.1021/jp801601h.

Gilles, C., P. Bonville, H. Rackoto, J. M. Broto, K. K. W. Wong, and S. Mann (2002), Magnetic hysteresis and superantiferromagnetism in ferritin nanoparticles, J. Magn. Magn. Mater., 241, 430-440, doi:10.1016/S0304-8853(01) 00461-9.

Gossuin, Y., P. Gillis, A. Hocq, Q. L. Vuong, and A. Roch (2009), Magnetic resonance relaxation properties of superparamagnetic particles, WIREs Nanomed. Nanobiotechnol., $1,299-310$.
Guyodo, Y., A. Mostrom, R. L. Penn, and S. K. Banerjee (2003), From nanodots to nanorods: Oriented aggregation and magnetic evolution of nanocrystalline goethite, Geophys. Res. Lett., 30(10), 1512, doi:10.1029/2003GL017021.

Guyodo, Y., S. K. Banerjee, R. L. Penn, D. Burleson, T. S. Berquo, T. Seda, and P. Solheid (2006), Magnetic properties of synthetic six-line ferrihydrite nanoparticles, Phys. Earth Planet. Inter., 154, 222-233, doi:10.1016/j.pepi.2005.05.009.

Harrington, R., D. B. Hausner, W. Xu, N. Bhandari, F. M. Michel, G. E. Brown Jr., D. R. Strongin, and J. B. Parise (2011), Neutron pair distribution function study of two-line ferrihydrite, Environ. Sci. Technol., 45, 9883-9890, doi:10.1021/es2020633.

Hochella, M. F., Jr., S. K. Lower, P. A. Maurice, R. L. Penn, N. Sahai, D. L. Sparks, and B. S. Twining (2008), Nanominerals, mineral nanoparticles, and Earth systems, Science, 319, 1631-1635, doi:10.1126/science.1141134.

Hunt, C. P., B. M. Moskowitz, and S. K. Banerjee (1995), Magnetic properties of rocks and minerals, in Rock Physics \& Phase Relations: A Handbook of Physical Constants, AGU Ref. Shelf, vol. 3, edited by T. J. Ahrens, pp. 189-204, AGU, Washington, D. C., doi:10.1029/RF003p0189.

Jambor, J. L., and J. E. Dutrizac (1998), Occurrence and constitution of natural and synthetic ferrihydrite, a widespread iron oxyhydroxide, Chem. Rev., 98, 2549-2586, doi:10.1021/ cr970105t.

Janney, D. E., J. M. Cowley, and P. R. Buseck (2000), Structure of synthetic 2-line ferrihydrite by electron nanodiffraction, Am. Mineral., 85, 1180-1187.

Janney, D. E., J. M. Cowley, and P. R. Buseck (2001), Structure of synthetic 6-line ferrihydrite by electron nanodiffraction, Am. Mineral., 86, 327-335.

Jansen, E., A. Kyek, W. Schäfer, and U. Schwertmann (2002), The structure of six-line ferrihydrite, Appl. Phys. A, 74, 1004-1006, doi:10.1007/s003390101175.

Lewin, A., G. R. Moore, and N. E. Le Brun (2005), Formation of protein-coated iron minerals, Dalton Trans., 2005, 3597-3610, doi:10.1039/b506071k.

Maillot, F., G. Morin, Y. Wang, D. Bonnin, P. Ildefonse, C. Chaneac, and G. Calas (2011), New insight into the structure of nanocrystalline ferrihydrite: EXAFS evidence for tetrahedrally coordinated iron(III), Geochim. Cosmochim. Acta, 75, 2708-2720, doi:10.1016/j.gca.2011.03.011.

Manceau, A. (2009), Evaluation of the structural model for ferrihydrite derived from real-space modeling of high-energy X-ray diffraction data, Clay Miner., 44, 19-34, doi:10.1180/ claymin.2009.044.1.19.

Manceau, A., and V. A. Drits (1993), Local structure of ferrihydrite and feroxyhite by EXAFS spectroscopy, Clay Miner., 28, 165-184, doi:10.1180/claymin.1993.028.2.01.

Michel, F. M., L. Ehm, S. M. Antao, R. L. Penn, P. J. Chupas, G. Liu, D. R. Strongin, M. A. A. Schoonen, B. L. Phillip, and J. B. Parise (2007), The structure of ferrihydrite, a nanocrystalline material, Science, 316, 1726-1729, doi:10.1126/ science. 1142525 .

Muller, R. N., L. Vander Elst, A. Roch, J. A. Peters, E. Csajbok, P. Gillis, and Y. Gossuin (2005), Relaxation by metal-containing nanosystems, Adv. Inorg. Chem., 57, 239-292, doi:10.1016/ S0898-8838(05)57005-3.

Murad, E. (1988), The Mossbauer spectrum of "well"-crystallized ferrihydrite, J. Magn. Magn. Mater., 74, 153-157, doi:10.1016/ 0304-8853(88)90062-5.

Néel, L. (1949), Théorie du traînage magnétique des ferromagnétiques en grains fins avec applications aux terres cuites, Ann. Geophys., 5, 99-136. 
Pearce, C. I., C. M. B. Henderson, R. A. D. Pattrick, G. van der Laan, and D. J. Vaughan (2006), Direct determination of cation site occupancies in natural ferrite spinels by $\mathrm{L}_{2,3} \mathrm{X}$-ray absorption spectroscopy and X-ray magnetic circular dichroism, Am. Mineral., 91, 880-893, doi:10.2138/am.2006.2048.

Penn, R. L., K. Tanaka, and J. J. Erbs (2007), Size dependent kinetics of oriented aggregation, J. Cryst. Growth, 309, 97-102, doi:10.1016/j.jcrysgro.2007.09.011.

Rancourt, D. G., and J. F. Meunier (2008), Constraints on structural models of ferrihydrite as a nanocrystalline material, Am. Mineral., 93, 1412-1417, doi:10.2138/am.2008.2782.

Rancourt, D. G., D. Fortin, T. Pichler, P.-J. Thibault, G. Lamarche, R. V. Morris, and P. H. J. Mercier (2001), Mineralogy of a natural As-rich hydrous ferric oxide coprecipitate formed by mixing of hydrothermal fluid and seawater: Implications regarding surface complexation and color banding in ferrihydrite deposits, Am. Mineral., 86, 834-851.

Rogalev, A., J. Goulon, C. Goulon-Ginet, and C. Malgrange (2001), Magnetism and Synchrotron Radiation, Lect. Notes Phys., vol. 565, Springer, Berlin.

Sainctavit, P., C. Cartier dit Moulin, and M.-A. Arrio (2003), Magnetic measurements at the atomic scale in molecular magnetic and paramagnetic compounds, in Magnetism: Molecules to Materials I, edited by J. S. Miller and M. Drillon, pp. 131-153, Wiley-VCH, Salt Lake City, Utah.

Schwertmann, U., L. Carlson, and E. Murad (1987), Properties of iron oxides in two Finnish lakes in relation to the environment of their formation, Clays Clay Miner., 35 297-304, doi:10.1346/CCMN.1987.0350407.

Sikora, M., A. Juhin, T.-C. Weng, P. Sainctavit, C. Detlefs, F. M. F. de Groot, and P. Glatzel (2010), Strong K-edge magnetic circular dichroism observed in photon-in/photon-out spectroscopy, Phys. Rev. Lett., 105, 037202, 1-4.

Thole, B. T., G. van der Laan, J. C. Fuggle, G. A. Sawatzky, R. C. Karnatak, and J.-M. Esteva (1985), 3d x-ray-absorption lines and the $3 \mathrm{~d}^{9} 4 \mathrm{f}^{\mathrm{n}+1}$ multiplets of the lanthanides, Phys. Rev. B, 32, 5107-5118, doi:10.1103/PhysRevB.32.5107.

Vayssières, L., C. Chaneac, E. Tronc, and J. P. Jolivet (1998), Size tailoring of magnetite particles formed by aqueous precipitation: An example of thermodynamic stability of nanometric oxide particles, J. Colloid Interface Sci., 205, 205212, doi:10.1006/jcis.1998.5614.

Wang, Y., G. Morin, G. Ona-Nguema, N. Menguy, F. Juillot, E. Aubry, F. Guyot, G. Calas, and G. E. Brown Jr. (2008), Arsenite sorption at the magnetite-water interface during aqueous precipitation of magnetite: EXAFS evidence for a new arsenite surface complex, Geochim. Cosmochim. Acta, 72, 2573-2586, doi:10.1016/j.gca.2008.03.011.

Zhao, J., F. E. Huggins, Z. Feng, and G. P. Huffman (1994), Ferrihydrite: Surface structure and its effects on phase transformation, Clays Clay Miner., 42, 737-746, doi:10.1346/ CCMN.1994.0420610. 